\title{
Safety of Completion Thyroidectomy for Initially Misdiagnosed Thyroid Carcinoma
}

\author{
Gangiti Kranthikumar, M.S., Nusrath Syed, M.S., D.N.B., Hemantkumar \\ Nemade, M.S., F.H.N.S.O.*, Satish Pawar, M.S., D.N.B., L. M. Chandra Sekhara \\ Rao, S.M.S., D.N.B., P.D.C.C., M.Ch., and T. Subramanyeshwar Rao, M.S., M.Ch. \\ Department of Surgical Oncology, Basavatarakam Indo-American Cancer Hospital and Research \\ Institute, Hyderabad, India
}

\begin{abstract}
Introduction: Completion thyroidectomy is defined as the surgical removal of the remnant thyroid tissue following procedures of less than total or near-total thyroidectomy. Whether thyroid reoperations are associated with an increased complication risk is controversial.

Objective: A retrospective analysis was done of patients undergoing completion thyroidectomy for cancer of the thyroid who had undergone surgery elsewhere for solitary thyroid nodule. The incidence of surgical complications in these patients after reoperation was investigated in this study.

Material and methods: The study included a total of 53 patients who had undergone thyroid lobectomy for a solitary nodule as initial surgery elsewhere and were referred to our institute for completion thyroidectomy when the histopathology revealed malignancy.

Results: There were 53 patients, 43 females and 10 males. Their mean age was $34.7 \pm 12.12$ years (range 1965 years). After initial surgery, the histopathology revealed papillary carcinoma in 46 patients (86.8\%), follicular carcinoma in 7 (13.2\%). Fourteen out of 53 patients had recurrent laryngeal nerve palsy after initial surgery (26.4\%). None of the patients had clinical hypocalcemia after the first surgery. One or more parathyroid glands were identified and preserved in 52 patients (98.1\%) in the process of completion thyroidectomy. No patient had additional recurrent nerve injury at the second surgery. The mean serum
\end{abstract}

\footnotetext{
Abbreviations: FNAC, fine-needle aspiration cytology; RLN, recurrent laryngeal nerve.

Citation: Kranthikumar G, Syed N, Nemade H, Pawar S, Rao LMCS, Rao TS. Safety of Completion Thyroidectomy for Initially Misdiagnosed Thyroid Carcinoma. Rambam Maimonides Med J 2016;7 (3):eoo22. doi:10.5041/RMMJ.10249

Copyright: (C) 2016 Kranthikumar et al. This is an open-access article. All its content, except where otherwise noted, is distributed under the terms of the Creative Commons Attribution License (http://creativecommons.org/licenses/by/3.0), which permits unrestricted use, distribution, and reproduction in any medium, provided the original work is properly cited.

Conflict of interest: No potential conflict of interest relevant to this article was reported.

* To whom correspondence should be addressed. E-mail: drhemantnemade@gmail.com
} 
calcium value preoperatively was $8.96 \pm 0.39 \mathrm{mg} / \mathrm{dL}$, and six months after surgery serum calcium was $8.74 \pm 0.56 \mathrm{mg} / \mathrm{dL}$. Mean follow-up was 18 months. Transient hypoparathyroidism occurred in $24.5 \%$ patients. Five patients were lost to follow-up. Permanent and symptomatic hyperparathyroidism occurred in eight patients (16.67\%).

Conclusions: Completion thyroidectomy is a safe and appropriate option in the management of welldifferentiated thyroid cancer. It removes disease on the ipsilateral and contralateral side of the thyroid and carries a low risk of recurrent laryngeal nerve damage, but a higher risk of permanent hypoparathyroidism.

KEY WORDS: Completion thyroidectomy, hypoparathyroidism, recurrent laryngeal nerve palsy, revision thyroid surgery, thyroid cancer

\section{INTRODUCTION}

Solitary thyroid nodule is one of the common presentations in a thyroid clinic. The usual evaluation for the solitary thyroid nodule includes fineneedle aspiration cytology (FNAC), which in many cases is inconclusive. This mandates hemithyroidectomy followed by completion thyroidectomy in the majority of the cases of well-differentiated carcinoma. Ultrasonography and FNAC has led to a 35\%$75 \%$ decrease in the number of patients requiring surgery. ${ }^{1-4}$ As a result, there has been a substantial increase in the proportion of malignant lesions in surgical cases. Completion thyroidectomy is traditionally believed to increase complication rates, but many studies contradict this belief.5-13

We analyzed our data to discover whether completion thyroidectomy increased the incidence of recurrent nerve palsy and parathyroid glandrelated complications. Furthermore, we investigated the data in terms of ipsilateral and contralateral sides (i.e. the previously operated side and the side untouched in the previous surgery, respectively).

\section{MATERIAL AND METHODS}

Data were obtained for patients who underwent surgery for solitary thyroid nodule elsewhere, including from nursing homes with surgeons not trained in head and neck oncology, and were referred to our institute for completion thyroidectomy after a postoperative histological diagnosis of cancer.

Some patients were referred specifically because of the complications during previous surgery, such as recurrent laryngeal nerve palsy. Medical records and details of 53 such patients who met the above criteria and underwent completion thyroidectomy between June 2012 and June 2014, with a mean follow-up of 18 months and a minimum of one year, were collected.
All patients underwent thorough clinical examination and neck ultrasonography, thyroid hormone assessment, and indirect laryngoscopy before the second operation. All the histological slides and blocks of the first surgery were reviewed by the pathology experts. Only patients with confirmed diagnosis of papillary thyroid carcinoma with tumor $>2 \mathrm{~cm}$, and all follicular carcinomas, were enrolled in the study of patients who underwent completion thyroidectomy. Serum calcium levels were determined preoperatively and postoperatively after 48 hours. All symptomatic patients were started on oral and intravenous calcium supplementation, and asymptomatic patients with hypocalcemia signs were started on oral calcium supplementation. All patients underwent vocal cord assessment after the second surgery at the time of discharge. Postoperatively all patients with papillary and follicular carcinomas were referred for radioiodine ablation. Thereafter patients were followed every six months with serum thyroid-stimulating hormone, serum thyroglobulin, serum antithyroglobulin, and serum calcium.

\section{Surgical Technique}

A single dose of antibiotic was administered just before the incision. The previous incision was revised and extended if necessary. After elevating subplatysmal flaps and retracting strap muscles in the midline, both sides of the thyroid or thyroid bed and the isthmus were carefully evaluated for any thyroid tissue. Meticulous dissection was performed, sometimes approaching the thyroid gland laterally from the strap muscles. Surgical loupes were used during surgery. A nerve monitor was not used. The superior laryngeal nerve, recurrent laryngeal nerve (RLN), and parathyroid glands were identified before resecting thyroid tissue. Where required, appropriate neck dissection was done. The central compartment was dissected only for locally advanced 
disease or when preoperative ultrasonography or intraoperative assessment revealed suspicious nodes in that region. At the end of the procedure if the parathyroid tissue appeared devascularized it was implanted in the sternocleidomastoid muscle.

\section{RESULTS}

There were 53 patients, 43 women and 10 men. Their mean age was 34.7 years (range $19-65$ years) (Table 1). The period between initial and second surgery ranged from 10 days to 150 days, with a median of 60 days. Mean operating time was 68 min. After initial surgery, the histopathology revealed papillary carcinoma in 47 patients $(86.8 \%)$ and follicular carcinoma in 6 (13.2\%). Fourteen out of 53 patients had recurrent laryngeal nerve palsy after initial surgery (26.4\%). One or more parathyroid glands were identified and preserved in 52 patients (98\%); parathyroids could not be identified in one patient. No patient had additional recurrent

\section{Table 1. Patient Demographics.}

\begin{tabular}{|c|c|}
\hline Patient and Surgery Details & $n$ \\
\hline \multicolumn{2}{|l|}{ Age Group } \\
\hline$<20$ & 2 \\
\hline $20-40$ & 38 \\
\hline $40-60$ & 10 \\
\hline$>60$ & 3 \\
\hline \multicolumn{2}{|l|}{ Sex } \\
\hline Male & 10 \\
\hline Female & 43 \\
\hline \multicolumn{2}{|l|}{ Surgery } \\
\hline $\begin{array}{l}\text { Subtotal thyroidectomy, } B / L \text { MRND } \\
\text { [including } B / L \text { paratracheal (central } \\
\text { compartment) node dissection] }\end{array}$ & 12 \\
\hline Subtotal thyroidectomy & 13 \\
\hline $\begin{array}{l}\text { Lobectomy, } \mathrm{B} / \mathrm{L} \text { paratracheal (central } \\
\text { compartment) node dissection }\end{array}$ & 10 \\
\hline Hemithyroidectomy only & 4 \\
\hline Lobectomy only & 14 \\
\hline \multicolumn{2}{|l|}{ Pathology } \\
\hline Papillary carcinoma & 47 \\
\hline Follicular carcinoma & 6 \\
\hline
\end{tabular}

B/L, bilateral; MRND, modified radical neck dissection.
Table 2. Complications.

\begin{tabular}{|l|c|}
\hline Complications & $n(\%)$ \\
\hline After First Surgery & \\
$\quad$ RLN palsy & $14(26.4 \%)$ \\
Hypocalcemia & 0 \\
After Second Surgery & \\
$\quad$ Additional RLN palsy & 0 \\
Lost to follow-up & $5(9.4 \%)$ \\
$\begin{array}{l}\text { Transient } \\
\text { hypoparathyroidism }\end{array}$ & $13 / 53(24.5 \%)$ \\
$\begin{array}{l}\text { Permanent } \\
\text { hypoparathyroidism } \\
\text { Mortality }\end{array}$ & $8 / 48(16.67 \%)$ \\
\hline
\end{tabular}

RLN, recurrent laryngeal nerve.

nerve injury at the second surgery. The mean serum calcium value preoperatively was $8.96 \pm 0.39$, and postoperative serum calcium was $8.74 \pm 0.56$ after six months. No patient required readmission. Mean follow-up was 18 months. Transient hypoparathyroidism occurred in $13(24.5 \%)$ patients. Five patients were lost to follow-up. Permanent and symptomatic hypoparathyroidism occurred in eight patients (8/48 patients, 16.67\%) (Tables 2 and 3).

There was no mortality and no chylous leak. There was no additional RLN injury, and the mean pre- and post-completion thyroidectomy serum calcium levels were $8.96 \pm 0.39 \mathrm{mg} / \mathrm{dL}$ and $8.74 \pm 0.56$ $\mathrm{mg} / \mathrm{dL}$, respectively. No patient developed wound infection or hematoma requiring exploration.

Thirteen patients had temporary hypocalcemia, whereas eight patients had permanent and symptomatic hypoparathyroidism. Five patients in the postoperative course of six months regained a normal serum calcium level without need of supplementation. Eight patients had persistent hypocalcemia and remained symptomatic, requiring oral calcium supplementation. Five of these patients had undergone bilateral paratracheal nodal dissection.

\section{DISCUSSION}

A completion thyroidectomy is required when papillary or follicular thyroid carcinoma is diagnosed postoperatively in patients undergoing partial thyroidectomy. It facilitates removal of the residual thyroid tissue/disease, permits screening and abla- 
Table 3. Second Surgery Type and Hypothyroidism.

\begin{tabular}{|l|c|}
\hline Surgery & $\begin{array}{c}\text { Cases of Permanent } \\
\text { Hypoparathyroidism }(\boldsymbol{n})\end{array}$ \\
\hline $\begin{array}{l}\text { Subtotal thyroidectomy, B/L MRND [including B/L paratracheal } \\
\text { (central compartment) node dissection] }\end{array}$ & 2 \\
Subtotal thyroidectomy & 1 \\
Lobectomy, B/L paratracheal (central compartment) node dissection & 3 \\
Hemithyroidectomy only & 1 \\
Lobectomy only & 1 \\
\hline
\end{tabular}

B/L, bilateral; MRND, modified radical neck dissection.

tion of metastatic disease with radioactive iodine, and allows for thyroglobulin level monitoring, thereby eliminating the risk of recurrence of the tumor and prolonging survival.

In addition, it is reported that presence of multifocal tumor is associated with a high risk of lymph node metastasis. ${ }^{11}$ Studies have reported residual tissue malignancy rates of $33 \%$ to $44 \%$ after the completion surgery..$^{-10}$ It was reported to be as high as $78 \%$ in Levin's series. ${ }^{12}$ Several authors have concluded that completion thyroidectomy is safe; associated morbidity and timing had no impact on development of complications. $5^{-13}$ The rate of the recurrent laryngeal nerve palsy varies from $0 \%$ to $4 \% .5^{-13}$

Although some studies recommend that completion thyroidectomy should be performed either before scar tissue development or after clinical remission of scar tissue, edema, and inflammation, recent evidence shows that timing of surgery has no effect on morbidity. ${ }^{10}$

Recurrent laryngeal nerve (RLN) injury can occur after thyroid surgery. The rate of RLN injury, mostly transient, ranges from $0.5 \%$ to $5 \% .{ }^{14}$ The risk is more important in patients who undergo reoperative thyroid surgery and in patients with thyroid cancer or hyperthyroidism. ${ }^{12}$ A meticulous surgical technique can lower the postoperative morbidity if precise operative rules are respected. Though the literature describes very low rates of recurrent laryngeal nerve injury during the primary thyroid surgery, in our series it was higher, probably because the majority of the cases were performed in nursing home setups by surgeons not trained in head neck oncology.
In our study there was no additional RLN injury in completion thyroidectomy. We used surgical loupes for meticulous dissection and identification of the nerves and parathyroid. A nerve monitor was not used in this study. Completion thyroidectomy was shown to be a fairly safe procedure, which carries a low incidence of complications and also facilitates further management and follow-up with radioactive iodine. There was no recurrent laryngeal nerve palsy in the study by El-Zohairy and Zaher. ${ }^{15}$ Similar results were noted with a $0 \%$ incidence of RLN injury when completion thyroidectomy was necessary for the treatment of thyroid malignancy, and it was effective for diagnosing and removing occult disease in the remaining thyroid by Kupferman et al. 5

In another study of 647 patients, conducted by Gulcelik et al. who compared groups for complications, there were no significant differences except temporary hypocalcemia between completion thyroidectomy and total thyroidectomy for differentiated thyroid carcinoma. ${ }^{16}$ The routine use of intraoperative neuromonitoring seems not to reduce the incidence of RLN during revision thyroid surgery, at least in the setting of a tertiary referral center. ${ }^{17}$

Hypocalcemia after thyroidectomy is the most common postoperative complication, with a reported incidence from $0.5 \%$ to even $50 \%$ of the operated patients. ${ }^{18}$

Transient hypoparathyroidism is said to be present when oral/intravenous calcium supplements are required for less than six months after surgery, and permanent hypoparathyroidism if hypocalcemia symptoms last more than six months or when the requirement for oral calcium/intravenous supplements lasts longer than six months. 
In a large series of 5,00o patients undergoing bilateral thyroid surgeries the overall incidence of transient and permanent hypoparathyroidism was $7.3 \%$ and $1.5 \%$, respectively. Extent of resection and surgical technique had a greater impact on the rates of permanent postoperative hypoparathyroidism than thyroid pathologic condition. ${ }^{19}$ Other series have reported an incidence of temporary hypoparathyroidism of $0 \%$ to $14 \%$, and a permanent hypoparathyroidism incidence around $2 \%$ to $8 \% .^{5^{-10,13,20-22}}$

With improvements in surgical technique and experience, complication rates of thyroidectomy performed for benign or malignant diseases are reduced. In spite of the improvement in surgical experience, temporary RLN palsy and hypoparathyroidism are the main complications in completion thyroidectomies, which need special attention. ${ }^{16}$

Hypocalcemia occurred more frequently when neck dissection was combined with total thyroidectomy $(60 \%)$ than without it $(17 \%)(P<0.005)$. The incidence of hypocalcemia was higher after central, than lateral, neck dissection. ${ }^{23}$ In a series by Roh et al. the incidence of temporary hypocalcemia was $46.3 \%$, and permanent hypocalcemia $4.9 \%$, in patients undergoing central compartment reoperation for recurrent/persistent differentiated thyroid cancer. ${ }^{24}$ Other series did not reveal increased morbidity following central compartment dissection. ${ }^{25,26}$

In our study, transient hypoparathyroidism occurred in 13 (24.5\%) patients. Five patients were lost to follow-up. Permanent and symptomatic hypoparathyroidism occurred in eight patients (8/48 patients, $16.67 \%)$.

We considered all patients for radioiodine ablation as the tumor size in previous histopathology reports could not be verified, and in a significant number of patients we found residual thyroid tissue in the previously operated thyroid bed.

\section{CONCLUSION}

Completion thyroidectomy is a safe and appropriate option in the management of well-differentiated thyroid cancer. It removes disease on ipsilateral and contralateral sides of the thyroid and carries a low risk of recurrent laryngeal nerve damage, but a higher risk of permanent hypoparathyroidism. The incidence of hypocalcemia was higher after central than lateral neck dissection. With improvements in surgical technique and knowledge, complication rates of completion or revision thyroidectomy are reduced.

\section{REFERENCES}

1. Al-Sayer H, Krukowski Z, Williams V. Fine needle aspiration cytology in isolated thyroid swellings: a prospective two year evaluation. Br Med J 1985;290: 1490-2. Full Text

2. Bisi H, Camargo R, Filho A. Role of fine needle aspiration cytology in the management of thyroid nodules: review of experience with 1925 cases. Diagn Cytopathol 1991;8:504-10. Full Text

3. Caplan R, Kisken W, Strutt P. Fine needle aspiration biopsy of thyroid nodules: a cost effective diagnostic plan. Wis Med J 1991;90:183-90. Full Text

4. Miller I, Hamburger J, Kim S. Diagnosis of thyroid nodules: use of fine needle aspiration and needle biopsy. JAMA 1979;242:481. Full Text

5. Kupferman ME, Mandel SJ, DiDonato L, Wolf P, Weber RS. Safety of completion thyroidectomy following unilateral lobectomy for well-differentiated thyroid cancer. Laryngoscope. 2002;112:1209-12. Full Text

6. Kim ES, Kim TY, Koh JM, et al. Completion thyroidectomy in patients with thyroid cancer who initially underwent unilateral operation. Clin Endocrinol (Oxf) 2004;61:145-8. Full Text

7. DeGroot LJ, Kaplan EL. Second operations for "completion" of thyroidectomy in treatment of differentiated thyroid cancer. Surgery 1991;110:936-40.

8. DeJong SA, Demeter JG, Lawrence AM, Paloyan E. Necessity and safety of completion thyroidectomy for differentiated thyroid carcinoma. Surgery 1992;112: 734-9.

9. Rosário PW, Fagundes TA, Borges MA, et al. Completion thyroidectomy in patients with thyroid carcinoma initially submitted to lobectomy. Clin Endocrinol 2004;61:652-3. Full Text

10. Auguste LJ, Attie JN. Completion thyroidectomy for initially misdiagnosed thyroid cancer. Otolaryngol Clin North Am 1990;23:429-39.

11. Chow SM, Law SC, Chan JK, Au SK, Yau S, Lau WH. Papillary microcarcinoma of the thyroid prognostic significance of lymph node metastasis and multifocality. Cancer 2003;98:31-40. Full Text

12. Levin KE, Clark AH, Duh QY, Demeure M, Siperstein AE, Clark OH. Reoperative thyroid surgery. Surgery 1992;111:604-9.

13. Makay O, Unalp O, Icoz G, Akyildiz M, Yetkin E. Completion thyroidectomy for thyroid cancer. Acta Chir Belg 2006;106:528-31. Full Text

14. Tresallet C, Chigot JP, Menegaux F. How to prevent recurrent nerve palsy during thyroid surgery? Ann Chir 2006;131:149-53. 
15. El-Zohairy M, Zaher AJ. Re-operation for the treatment of well differentiated thyroid cancer: necessity, safety and impaction on further management. $\mathrm{J}$ Egypt Natl Canc Inst 2004;16:130-6.

16. Gulcelik MA, Kuru B, Dincer H, et al. Complications of completion versus total thyroidectomy. Asian Pac J Cancer Prev 2012;13:5225-8. Full Text

17. Alesina PF, Rolfs T, Hommeltenberg S, Hinrichs J, Meier B, Mohmand W. Intraoperative neuromonitoring does not reduce the incidence of recurrent laryngeal nerve palsy in thyroid reoperations: results of a retrospective comparative analysis. World J Surg 2012;36:1348-53. Full Text

18. Proczko-Markuszewska M, Kobiela J, Stefaniak T, Lachinski AJ, Sledzinski Z. Postoperative PTH measurement as a predictor of hypocalcaemia after thyroidectomy. Acta Chir Belg 2010;110:40-4. Full Text

19. Thomusch O, Machens A, Sekulla C, Ukkat J, Brauckhoff M, Dralle H. The impact of surgical technique on postoperative hypoparathyroidism in bilateral thyroid surgery: a multivariate analysis of 5846 consecutive patients. Surgery 2003;133:180-5. Full Text

20. Kisaoglu A, Ozogul B, Akçay MN, et al. Completion thyroidectomy in differentiated thyroid cancer. When to perform? Ulus Cerrhai Derg 2014;30:18-21. Full $\underline{\text { Text }}$

21. Lefevre JH, Tresallet C, Leenhardt L, Jublanc C, Chigot JP, Menegaux F. Reoperative surgery for thyroid disease. Langenbecks Arch Surg 2007;392: 685-91. Full Text

22. Rafferty MA, Goldstein DP, Rotstein L, et al. Completion thyroidectomy versus total thyroidectomy: is there a difference in complication rates? An analysis of 350 patients. J Am Coll Surg 2007; 205:602-7. Full Text

23. Cheah WK, Arici C, Ituarte PH, Siperstein AE, Duh $\mathrm{QY}$, Clark OH. Complications of neck dissection for thyroid cancer. World J Surg 2002;26:1013-16. Full Text

24. Roh JL, Kim JM, Park CI. Central compartment reoperation for recurrent/persistent differentiated thyroid cancer: patterns of recurrence, morbidity, and prediction of postoperative hypocalcemia. Ann Surg Oncol 2011;18:1312-18. Full Text

25. Palestini N, Borasi A, Cestino L, Freddi M, Odasso C, Robecchi A. Is central neck dissection a safe procedure in the treatment of papillary thyroid cancer? Our experience. Langenbecks Arch Surg 2008; 393:693-8. Full Text

26. Kim MK, Mandel SH, Baloch Z, et al. Morbidity following central compartment reoperation for recurrent or persistent thyroid cancer. Arch Otolaryngol Head Neck Surg 2004;130:1214-16. Full Text 